\title{
Study on Optimization Design of Micro-Class of Information Technology Based on ADDIE Model
}

Shangling Song and Zhen You

\author{
Jining Polytechnic College, Shandong, China
}

\begin{abstract}
To meet the students' autonomous learning and fragmented learning needs, micro-class of information technology was proposed. To optimize the design of micro-class from systematic method, ADDIE model was proposed. ADDIE model can play more operational and practical guiding role in the design and performance. This article takes the interpretation of the concept of ADDIE as the breakthrough point, discussing the construction of the design of micro-class of information technology based on ADDIE Model.
\end{abstract}

Keywords:Micro-class;ADDIE model;Autonomous learning;

\section{Introduction}

At present, information technology teaching is facing new opportunities and challenges, micro-lesson as the product of "micro-era", it can be in line with the students' learning styles and cognitive characteristics, which is suitable for the students' autonomous learning and individual learning needs. It can provide an opportunity for the reform of information technology teaching.Information technology and micro -design course is a complex dynamic system, which is involved in all aspects of teaching and learning. It needs to be the instructional design model, which can help teachers to organize the design of micro-class with theory and method, so as to play a better role in guiding the performance of micro-class. In 1997, Merrienboer made research and believed that ADDIE model should be flexible when it is used in the specific context according to local conditions, which can be combined with other relevant teaching theories and designing principles effectively, so as to play its real role and achieve better effect. In recent years, some scholars believed that the ADDIE model can not only be a process model for instructional design, but more important is that it can provide people a kind of thought to solve the problems. Now, ADDIE model has had a wide influence on the field of education both at home and abroad.

\section{The Concept of ADDIE}

ADDIE is a kind of mature system model for the design of instructional design. The content can be including: What to learn? (learning objectives); How to learn? (learning strategies and how to inspect the effect of learning, namely, learning evaluation). The five letters of ADDIE can represent the following aspects 
respectively: Firstly, Analysis, it means before designing the curriculum, it should make analysis on a series of questions that are related to teaching, it can be including teaching objectives, task, the audience, the condition and the performance. Secondly, Design, which means the process of designing teaching activities. Thirdly, Development, which should be according to the completed framework of the designed curriculum, objectives, tasks, etc. to have the corresponding development. Fourthly, Implement, it should carry out teaching implementation according to the basis of the previous conditions for the design and development. Lastly, Evaluation, it should make evaluation on the implementation status and effect of learning on teaching.

ADDIE model, as a general teaching design model, it can represent a series of core steps of the designing process of teaching system, which has been recognized as effective system method to solve the demand of teaching design. Therefore, it can meet the needs of the teaching design of micro-class. In some degree, it is both feasible and necessary to combine them together.

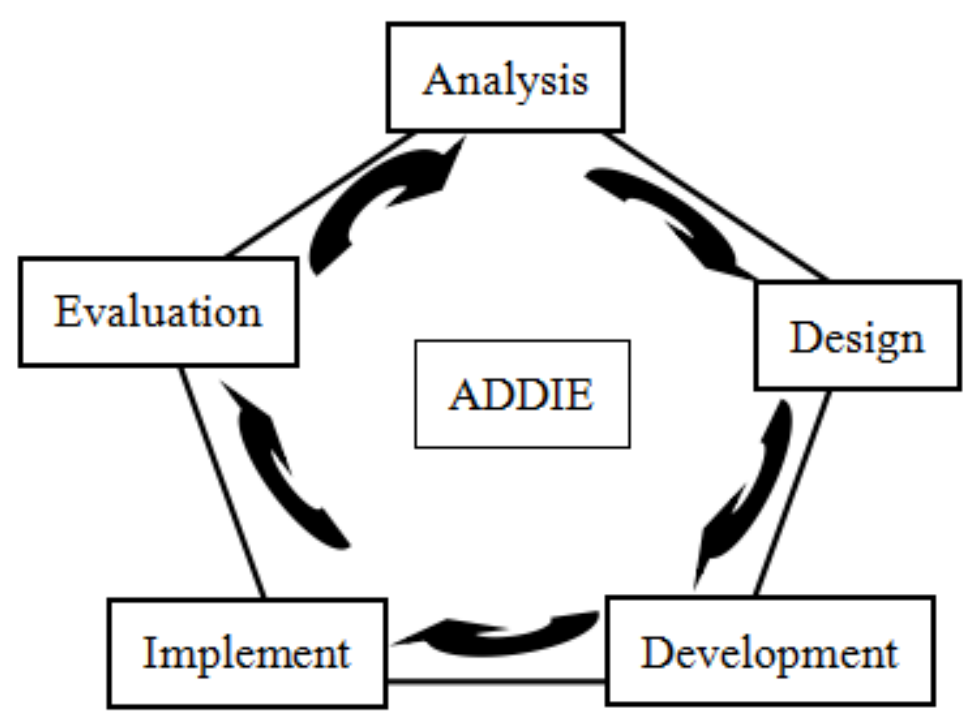

Fig. 1 The Teaching Design Model of ADDIE

\section{The Construction of the Design of Micro-Class of Information Technology Based on ADDIE Model}

According to ADDIE model, combined with the teaching design theory, this paper attempts to construct the process model of information technology of the teaching design of micro-class. Among them, in order to facilitate the clarity of the actual operation process, it put the evaluation as the independent stage in the final stage, although in each stage, it is required to penetrate the formation evaluation. The five steps, namely, analysis, design, development, implementation, evaluation will be divided into different sub-steps.

(1)The stage of analysis. The stage of analysis is the most important aspect of the teaching design, it needs to set teaching objectives, the objective factors as well as the 
learning needs. The set of the teaching should take ability as the orientation. According to the requirements of the teaching syllabus, the information technology teaching courses should cultivate students' application ability of information technology, which also should take it as the teaching goal. Therefore, analysis on any topic goals, it should need to consider the application of information technology in real life and work. In particular, micro-class is also the link of the overall teaching, which can not be completely separated from the teaching materials, apart from the entire learning unit. The current analysis on the existed resources refers to measuring the existed teaching resources, environmental resources, as well as the technical support and so on.

Table 1 The Classification of Micro-Class and Teaching Design

\begin{tabular}{|c|c|c|}
\hline $\begin{array}{c}\text { The Classification of } \\
\text { Micro-Class }\end{array}$ & Content & Teaching design \\
\hline $\begin{array}{l}\text { Basic knowledge of } \\
\text { information technology }\end{array}$ & $\begin{array}{c}\text { Common sense of } \\
\text { information technology, } \\
\text { operating system, software } \\
\text { system }\end{array}$ & Oral teaching method \\
\hline $\begin{array}{l}\text { Skills of operating } \\
\text { software }\end{array}$ & $\begin{array}{l}\text { Word processing, image } \\
\text { processing, multimedia } \\
\text { technology, network } \\
\text { technology }\end{array}$ & $\begin{array}{l}\text { Demonstration method for } \\
\text { operating }\end{array}$ \\
\hline $\begin{array}{c}\text { The algorithm of } \\
\text { information technology } \\
\text { and program }\end{array}$ & $\begin{array}{l}\text { The structure and } \\
\text { algorithm, the design and } \\
\text { development of simple } \\
\text { program }\end{array}$ & $\begin{array}{l}\text { Demonstration method for } \\
\text { operating }\end{array}$ \\
\hline
\end{tabular}

(2) The stage of design. Based on the full and comprehensive analysis , the stage of design needs to determine the teaching objectives, teaching process as well as the form of media and so on. As for the establishment of teaching goal, according to the requirements of the syllabus, it can usually be described from the four dimensions, namely, knowledge, skills, attitude, methods and strategies, which also can adopt the way of the targeted behavior to describe the learners abilities, especially in language skills, so as to see whether they can meet the requirements. One micro-class can only solve one problem that can be regarded as a breakthrough, which can not simply transfer all the objectives of the class directly to the micro-class.

(3) The stage of development. Through the front analysis, it has established the learning objectives, which can point out the direction for the micro-class. In this stage, through the visualization design of knowledge, it can make the knowledge points presented in a concise visual form. By using micro-courseware, it can summarizes the idea of the teaching design, add more knowledge to the expression of the knowledge, so as to achieve the effect of combing vision and audition, which can lay the foundation for the development of micro-video. 


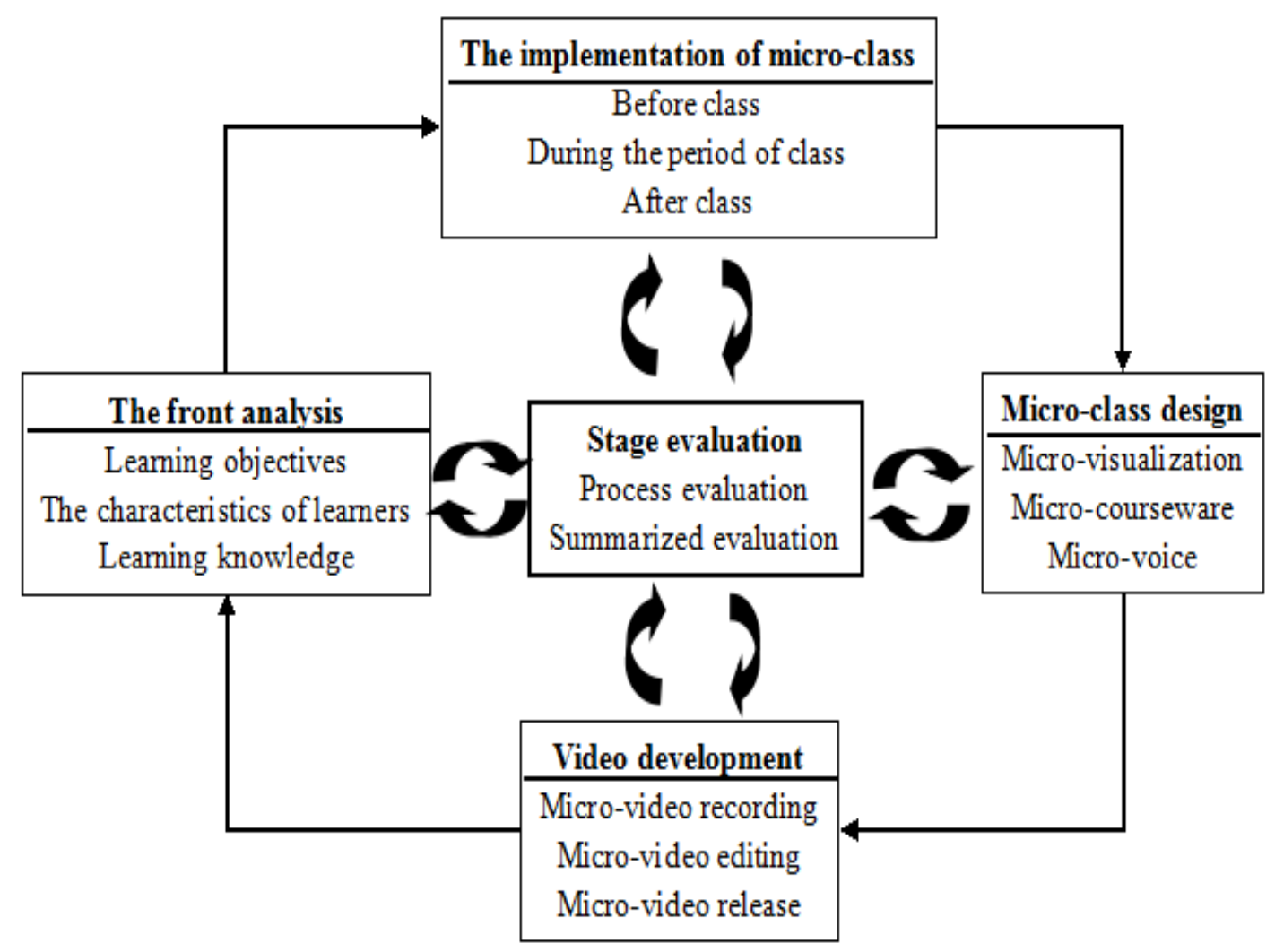

Fig.2 The Designing Model of Micro-Class

\section{Knowledge Points and Visual Design}

Knowledge visualization adopts the style of visual expression to improve the transmission of knowledge and information as well as the creation and communication between two persons or more than two persons. Teachers can use the knowledge visualization tools to have visual design for knowledge of information technology, which can make the ambiguous concept change into clear external morphology, so as to improve the level of the students' using knowledge in micro-class, which can promote students carry on more effective knowledge learning. As for knowledge visualization tools, it can be including flow diagram, the map of concept, the guiding map of thought, cognitive map, knowledge map, table and so on. The visualization design of knowledge points uses the idea and method of knowledge visualization design, according to the target of teaching knowledge points in micro-class, so as to design visual representations in a variety of visual images.

\section{Micro-Courseware and Language Design}

Micro-courseware is an important part of the micro-video, which is a simple and convenient multimedia expression, micro-courseware uses one knowledge point to unfold the related content, each page of it should be clear and concise, it's better to illustrate one point of information or information block, which can not design too many pages. At the same time, it should reduce the transmission between the pages as 
far as possible, so as to be in accordance with the logical structure of knowledge and the learning process of students. The reasonable use of navigation menus and clear learning path can combine the designing results of knowledge visualization with micro-courseware.

\section{Conclusion}

The effective integration of ADDIE model and micro-course design of information technology disciplines follows the rules of micro-class design, which can improve the efficiency of micro-class design, so as to ensure the realization of micro-teaching objectives. It can cultivate and improve students' information literacy, a t the same time. But the application of ADDIE model of the design of micro-course information in technology disciplines is still in the initial exploring stage, it needs researchers and information technology teachers to further strengthen the study of theory and practice.

\section{Reference}

[1]Myung-Suk Lee, Yoo-Ek Son. 2012. A Study on the Adoption of SNS for Smart Learning in the Creative Activity. International Journal of Education and Learning. vol.121, pp1-18.

[2]Rasmus Ulslev Pedersen. 2010. Micro Information Systems and Ubiquitous Knowledge Discovery. Michael. May\&Lorenza. Saitta. Ubiqui-tousKnowledge Discovery. Berlin Heidelberg :Springer-Ver-lag. pp216-234.

[3]Jon Aleckson. 2012. Video as eLearning:15 Tips. http://managinge-learning.com/ 2012/10/12/ video-as-elearning/.

[4]Engel, R. A. Jr. L. D. 1972. Weller, Mini-Courses: Maxi-Morale. The High School Journal. vol.56, pp142-149.

[5]Dwight W. 1966. Allen.Micro-teaching: A New Framework for In-service Education. The High School Journal. vol.8, pp355-362. 